\section{Gategory}

Synthesis of

Heterocycles

\section{Key words}

palladium catalysis

carbonylative Heck reaction

arylfuranones

J. SCHRANCK, X.-F. WU, A. TLILI, H. NEUMANN, M. BELLER* (LEIBNIZ-INSTITUT FÜR KATALYSE E.V. AN DER UNIVERSITÄT ROSTOCK, GERMANY)

A Novel Double Carbonylation Reaction of Aryl Halides: Selective Synthesis of 5-Arylfuranones

Chem. Eur. J. 2013, 19, 12959-12964.

\title{
Synthesis of 5-Arylfuranones via a Carbonylative Heck Reaction
}

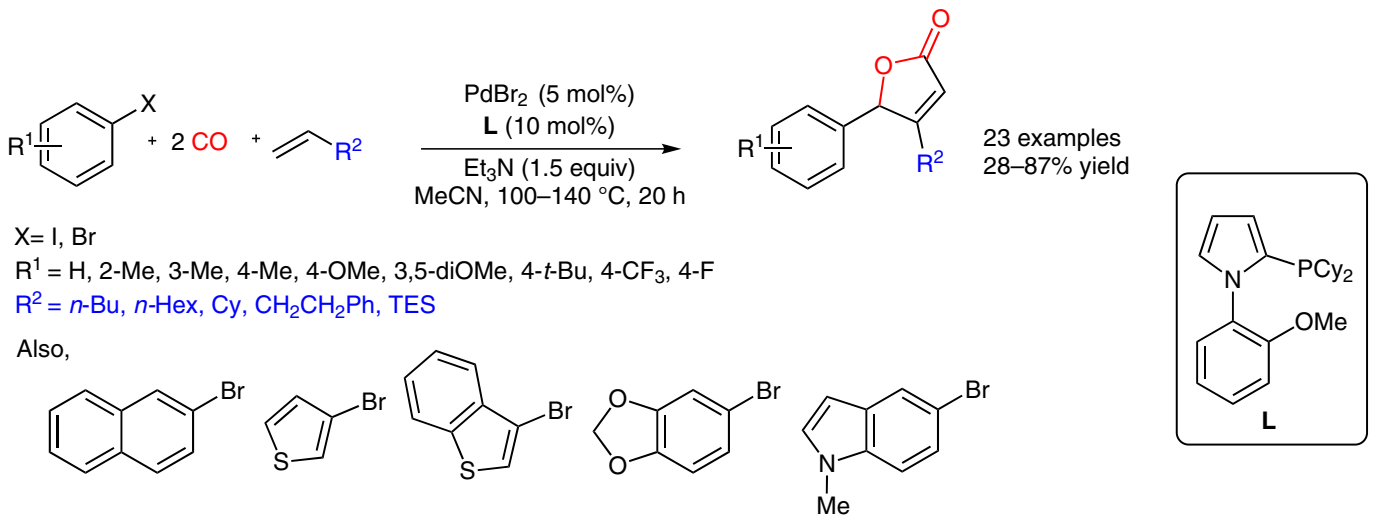

Significance: Reported is the synthesis of 5-arylfuranones by the three-component reaction of aryl halides, carbon monoxide, and alkenes in the presence of $\mathrm{PdBr}_{2}$, cataCXium POMeCy as ligand $\mathbf{L}$ and triethylamine as base. In the exploration of the scope of the reaction, substituted aryl bromides, aryl iodides, and different alkenes were tested. Aryl bromides bearing electron-donating groups $\left(\mathrm{R}^{1}=t\right.$-Bu, 3-OMe, 4-OMe) led to furanones in 55-77\% yield. However, aryl and alkyl bromides with electron-withdrawing groups, such as 4-bromoacetophenone, 4-bromoacetaldehyde and 4-bromobenzonitrile produced only trace amounts of products. Some bromo heterocycles including bromothiophene, bromobenzothiophene, benzodioxole, and indole derivatives were also tolerated. Terminal alkenes with $\mathrm{R}^{2}=n-\mathrm{Bu}$, Cy, TES afforded furanones in $54-73 \%$ yield, while an alkene with $\mathrm{R}^{2}=\mathrm{CH}_{2} \mathrm{CH}_{2} \mathrm{Ph}$ form the desired product in only $28 \%$ yield with a greater amount of the isomeric 3-alkyl-5-aryl-substituted furanone being formed.
Comment: Synthetic furanone compounds have been shown to inhibit bacterial quorum sensing in $P$. aeruginosa and to exhibit favorable therapeutic effects on $P$. aeruginosa lung infection $(\mathrm{H}$. Wu et al. J. Antimicrob. Chemother. 2004, 53, 1054). In the present double carbonylative Heck reaction, optimization of the reaction using different ligands, solvents, and the effect of carbon monoxide pressure was explored; increasing the carbon monoxide pressure from 5 to 20 bar resulted in improved yield. Use of inorganic base in the reaction failed to give furanone products. Similar reactivity was observed when aryl iodides were employed in place of aryl bromides. 